\title{
SPOORWEGEN IN NEDERLANDSCH INDIE
}

Bij den grooten strijd over de spoorwegen in Nederland, werd door velen tot heden weinig gedacht aau ous aanzienlijk rijksgebied in Azie, alwaar een enkel eiland, welks oppervlakte toch nog maar het $\frac{1}{1^{2}}$ van ouze rijksbezittingen uitmaakt, jaarlijks bijna honderd millioen waarde aan produkten voor onzen handel en scheepvaart oplevert. Zouden dáírir geen spoorwegen noodig zijn? Het zou eeu groote mate van onkunde verraden, indien men meende, dat Java zoo voldoende van middelen van vervoer en gemeenschap is voorzien, dat de behoefte an spoorwegen minder zou bestaan en gevoeld worden, dan hier te lancle! Een enkel feit zal toereikend zijn om dit te bewijzen. $\mathrm{Nu}$ weinige jaren geleden kostte de rijst, het hoofdvoedsel der bevolking, op de eene plaats $f 20$ de pikol terwijl ze in eene andere provincie, op niet meer dan 30 en 40 uren afstand, voor $f 4$ verkocht wẹrd; dáúr leefde men betrekkelijk in overvloed, terwijl meu ginds niet kon voorzien in de dringende nooddruft der bevolking, die zich van al het geldswaardige, zelfs het ploegvee en de landbouw-gereedschappen, moest ontdoen, om den honger te bevredigen. Dit feit alleen, ofschoon het zich meermalen, zij het dan ook in geringere mate, vertoond heeft, zou meenen wij, reeds voldoende zijn om de noodzakelijkheid van spoorwegen aan te toonen, indien niet bovendien de uitbreiding der partikuliere kultuur, vooral van koffij en suiker, grootelijks belemmerd en belet werd, door het gebrek aan voldoende wegen en middelen van vervoer, om niet te spreken van de gouvernements kultuur, die er evenzeer door bezwaard wordt.

Op het oogenblik dat men zich in Nederland voorstelt een groot aantal millioenen, van het Indisch batig slot, tot den aanleg van spoorwegen te besteden, kan het welligt eenig nut hebben, de aandacht ook meer bepaald te vestigen op de dringende behoefte ans spoorwegen op Java, alwaar de middelen van vervoer, door het niet in verhouding van landontginning en produktie, toenemen van den veestapel, van jaar tot jaar moeijelijker en kostbaarder wordt, waarvan bet laatste handelsverslag (1859) van Samarang bewijzen levert, die noodwendlig nadeelig op onzen handel en fabrieknijverheid mocten terug werken. 
In dat verslag leest men bladz. 1 "Over het algemeen is de handel in het afgeloopen jaar minder belangrijk geweest dau in 1858. In den loop van dit verslag zullen de oorzaken worlen angewezen, die niet alleen uitbreiding van het handelsverkeer dezer plaats in den weg staan, maar die, wanneer zij niet worden weggenomen, een trapswijzen achteruitgang onvermijdelijk maken."

Bladz. 13. "Ofschoon de invoer van paarden dien ran het jaar 1858 met 40 pCt. ovcrtrof, was dezelve toch niet geevenredigd aan de beloeften, zooals blijkt uit het steeds toenemeu der prijzen. In het handelsverslag van 1858 werd gewezen op het jaarlijks duurder en schaarscher worden van transportmilldelen voor den vervoer van goederen; met meer nadruk nog moet thans daarop terug gekomen worden, daar men nog in geen jaar met zoo vele moeijelijklieden hceft te kampen gehad, bij den op- en afroer van goederen naar en van de binnenlanden als in 1859."

Bladz. 22. „De oorzaken dat de handel van Samarang in 1859 over het algemeen meer afgenomen dan toegenomen is, liggen voor de hand, indien dezelve blijven bestaan zal het handelsverkeer dezer plaats meer en meer achteruit gaan. De oorzaken zijn voornamelijk de betreurenswaardige thestand der communicatien met de binnenlanden cn de nog immer zeer gebrekkige gemeenschap met de Reede. Wat het eerste betreft, zoo is het vervoer van goederen naar en uit de binnenlanden zoo moeijelijk en meer en meer kostbaar geworden, ten gevolge van den staat der karrenuegen en het zoo zeer afnemen van het aantal treken lastdieren, van welke jaarlijks zoovele omkomen - dat deze staat van zaken dringend voorziening vordert. Zulks gaf dan ook den landhuurders te Sourakarta aanleiding zich eenparig tot den opperlandvoogd te wenden met een gemotiveerd adres, in hetwelk de tegenwoordige toestand zakelijk werd niteengezet en de medewerking dringend ingeroepen, tot daarstelling van eenen ijzeren spoorweg van de binnenlanden naar Samarang; dit adres werd ook door den handel van Samarang met aandrang ondersteund, als het eenige middel om de gemeenselap met de binnenlanden speciaal voor het vervoer van goederen te verbeteren en in verband te brengen met de eischen van den tijd. Voor Samarang is zulks eene levenskwestie. Ook de handel en industrie in Nederland hebben bij deze aangelegenheid een groot belang, want ontwijfelbaar zal het verbruik van alle Europesche goederen, inzonderleid ran ïjnoaden, anzienlijk toenemen onder de talrijke bevolking der binnen-residentien, wanneer het transport der goederen regelmatiger en met minder moeite, tijdverlies en kosten kan geschieden dan nu het geval is. Hoo bezwarend die kosten zijn blijkt wanneer men be- 
denkt - om maar iets te noemen - dat de prijs van een stuk katoen, bij vervoer van hier (Samarang) naar de (25 à 30 uren verwijderde) residentien Sourakarta en Djocjacarta, alleen aan transportkosten, wordt verhoogd met 20 à 30 cents, waarbij het zeker niet zal blijven, terwijl hierbij nog komt dat, om het vervoeren met draagpaarden doenlijk te maken, katoenen goederen van derzelver originele emballage moeten ontdaan en, los gepakt, in matten moeten worden getransporteerd, hetgeen almede kosten veroorzaakt, en de goederen gedurende de reis ook meer an beschadiging bloot stelt. Aan het vervoeren van zware goederen, machinerien enz., van welke zoo vele van belang zijn voor de exploitatie van landen, valt niet te denken. De transportkosten van een pikol koffij of suiker van uit de residentien Soerakarta en Djocjocarta bedragen thans al $f 2$ à $f 2 \frac{1}{2}$, zonder dat men zelfs daarvoor transportmiddelen in verhouding met de produktie kan vinden. Ook voor deze produkten is een spoorweg dringend noodig, en verdient hierbij almede de aandacht de uitnemende geschiktheid van een groot gedeelte der vorstenlanden voor de suikerkultuur, de ingenomenheid der bevolking aldaar met die kultuur en de gemakkelijkheid, waarmede men met haar vrijwillige overeenkomsten kan aangaan voor den aanplant. En evenwel beweert men dat zonder dwang de Javanen geen suikerriet zouden willen teelen. $\left({ }^{*}\right)$ „Het kostbare en moeijelijke transport (van de on-

$\left({ }^{*}\right)$ Ten annzien van het geheel welslagen van de vrijwillige suikerkultuur in de vorstenlanden, waarop door S. wordt verwezen, dient echter opgemerkt:

10 dat het in Djocjocarta nog niet als bewezen is aan te nemen, dat er genoegzame handen voor die kultuur zullen gevonden worden. Zijn wij wel onderrigt dan is verleden jaar het eerste riet voor Europesche markt in de residentie Djocjo geplant, en zal men voorzigtigheidshalve het welslagen nog niet onvoorwaardelijk mogren aannemen.

20 werd de indigo in Djocjo evenzeer vrijwillig geplant, als thans de suiker in een paar landen, zoodat het wel eenige bedenking kan hebben, met zoodanigen nadruk op de ingenomenlieid der bevolking met den vrijwilligen suikerriet-aanplant te verwijzen.

Hoe dit zij, het betoog van Dr. B. omtrent de noodzakelijkheid van spoorwegenaanleg wordt er niet door verminderd, want het is bepaald zeker, dat het gebrekkig vervoer, zoo als het thans bestaat, de uitbreiding der suikerkultuar te Solo (en te Djocjo indien zij slaagt) in den weg staat.

Ten betooge hierbij had nog kunnen worden aangehaald, dat de regering begonnen is de koffij nit Solo langs de Solorivier naar Sourabaija af te voeren, steeds nithoofde van hetzelfle gebrek aan transportmiddelen naar Samarang. Aangezicn nu echter de Solo-rivier alleen bevaarbaar is in den Westmousson, in de drie eerste maanden des jaars, zoo geeft dat vervoer voor koffj, die in Julij, Augustus en September disponibel komt, ecn groot oponthoud, en daardoor onvermijdelijk cen aanzienlijk verlies, zoo ann tijd als, dnardoor, ann rente.

RED. 
misbare machinerien en het produkt) staat alleen het toenemen der suikerpoduktie, in voornoemde streken, in den weg; wanneer dit bezwaar is opgeheven bestaat er geen twijfel aan eene aanzienlijke vermeerdering derzelve." "Het is dierhalve te hopen, dat de Regering zal willen medewerken tot daarstelling van een middel van gemeenschap, hetwelk in hooge mate de welvart en bloei van geheel midden-Java zoude bevorderen en waarvan de voordeelen voor het gouvernement, de inlandsche bevolking, handel en industrie niet te berekenen zijn."

Als men een blik op de kaart van Java slaat en ziet, dat voor de rijkst bevolkte en meest vruchtbare provincie van Midden-Java $\mathrm{Ba}$ gelen, Kadoe, Djocjocarta en Souracarta, de directe gemeenschap met de hooflplaats Samarang voor den af- en annvoer van produkten en goederen van allerlei aard onmisbaar is, dan zal men moeten erkennen, dat de bezorgdheid van den Samarangschen handel van veel beteekenis is en de meeste aandacht en een gezet onderzoek verdient, vooral wanneer. men met de statistiek van den veestapel in de hand, de overtuiging verkrijgt, dat de vermeerdering van trek- en draagvee, wel verre van met de toenemende partikuliere produktie gelijken tred t.e houden, integendeel in betrekking tot de behoefte vermindert. Tot 1846 scheen de volkswelvaart, zoo niet stationair, althans niet afnemende te wezen, voor zoo veel den rijkdom van den veestapel betreft, die jaarlijks gemiddeld met ruim $4 \mathrm{pCt}$. toenam.

In 1846 bedroeg het getal buffels en runderen $2,041.043$ paarden 349.288

-1839. " " " " " $" 1,550.742$ " 251.429

Toewas in 7 jaren . . . . . 490.301 paarden 97.859 jaarlijks gemid. . . . $70.043 \quad$ " 13.979 Van 1839 tot 1846 zijn op Java ingevoerd 21.960 paarden. Jaarlijks gemirddeld • . 3137 ",

Van 1846 af, sprongen de algemeene teekenen van af nemende welvaart jaurlijks al meer in het oog, vooral zigtbaar in hoornvee: in stede van eene jaarlijksche vermeerdering van 70,000 stuks, waren er in 1849 veel minder; het getal bedroeg toen $1,962,145$ dus werkelijk 70,000 beneden het getal van 1846 .

Nadat in 1850-1853 de grootste druk en misbruiken, die aan cle welvaart der bevolking knaagde, waren opgeheven, begon de algemeene toestand en ook de veestapel zich te verbeteren, echter nog niet in gelijke mate als vóór 1846, zoo als uit de Regeringsverslagen blijkt.

In 1857 bedroeg het getal buffels en runderen $2,383.640$ paarden 406.671

$" 1846 "$ " $" \quad " \quad$ " $" 2,041.043 \quad$ " 349.288

Vermeerdering in 11 jaren $\quad 342.597$ paarden 57.383

Van 1846 tot 1857 per jair * * ; j 31.127 " 5.217 gemiddeld in het jaar. 
In de laatste 11 jaren heeft dus de vermeerdering van hoornvee $2 / \%$ of ruim 4.00,000 stuks minder bedragen, dan in de zeven voorafgegane.

In 1846 bedroeg de bevolking op Gouvernements-grond 7,250,000 zielen, gezamenlijk bezaten zij $2,041,043$ stuks bufiels en runderen $=281$ stuks per 1000 zielen.

In 1857 bedroeg diezelfde bevolking 9,150,000 z.: de buffels en runderen $2,383,640=260$ stuks per $1000 \mathrm{z}$ : d. i. 192,000 stuks minder voor de totale bevolking.

Trekt men den jaarlijks gemiddelden invoer van paarden vall 1839$1846=3137$ stuks van de vermeerdering af $=13979$, dan heeft de jaarlijksche toewas bedragen 10,842 ; past men dezelfde berekening toe op de jaren 1847-1857, dan blijkt de toewas niet meer geweest te zijn dan $762=210,000$ stuks minder in de laatste 11 jaren. (*)

De behoefte aan trek- en draagvee is jaarlijks 750,000 stuks waarin, bij den verminderden toewas, door den aanvoer niet naar behooren kan voorzien worden; de handel heeft dus over zoo veel minder te beschikken dan 12 jaren vroeger; terwijl de partikuliere produktie sedert aanzienlijk is vooruitgegaan.

De gegeven cijfers stellen de gegrondheid der klagte en bezorgdheid van den Samarangschen handel in helder licht. Het gevolg moet zijn, dat er steeds hooger prijzen angeboden worden voor het vervoeren

(v) Zij, die de vernrming der Javanen bij den gedwongen arbeid blijven loochenen, dienden toch wel met even duidelijke feiten te bewijzen, dat de welvaart integendeel toeneemt, zij behoorden te bewijzen, dat deze betrekkelijke vermindering vin den veestapel een teeken van welvaart is, waarbij een millioen Javanen, bij gelijke prijzen, in 1857 een half millioen guldens minder rijk an vee is, dan in 1846.

B.

[Kan de verhouding van den veestapel tot de bevolking, (verondersteld dat de door het Gouvernement verkregen cijfers dien voldoende juist doen kennen) worden angenomen ecn duidelijke mantstaf te zijn van de verarming van Java's bevolking, ten gevolge van het heerschend arbeids-stelsel? Dat eene vermindering in den veestapel nadeelig is te achten, kan natuurlijk nict worden ontkend, doch er moet toeh ook eene omstandigheid in het oog worden gehouden, die, afyescheiden van de verminderde welvatart in het alyemeen, meer bijzonder op het getal buffels in Java van invloed is. - Inmers, door de meerdere ontginningen voor de Europeesche markt in de binnenlanden van Java, zijn er meer producten dan vroeger af te voeren, en ten gevolge darvan wordt er (uatuurlijk ten onregte) meer van de trekbecsten gevergd dan deze redelijk kunnen uithouden. De buffels worden, naar wij vermeenen, in de laatste jaren èn tc jong gebruikt, èn te zwaar bcladen, van daar grootere sterfte.

Dit nu is wel bepaald een ongunstig verschijnsel, doch het is niet zulk een doorgaand teeken van achteruitgang der bevolking, als wanneer men den veestapel, onder dczelfde omstandigheden, steeds door zag verminderen.

RED ] 
van goederen, die men niet, met hoop op eene gunstige verandering, kan laten liggen; tot elken prijs moeten zij in het bereik der verbruikers worden gebragt. De bezitters van het trek- en draagvee, door de groote voordeelen verlokt, zullen het al meer lasten opleggen en er meer van vergen dan het zonder nadeel dragen kan en de sterfte moet in dezelfde progressie toenemen en - zoo als in het handelsverslag is opgemerkt, - waarvan met wiskundige zekerheid het einde moet wezen, dat de te vervoeren waren, de énorme transportkosten niet meer kunnen dragen, de handel zich inkrimpen en tot het hoogst noodzakelijke zal moeten bepalen! In de binnenlanden zullen de produkten, van de plaats waar zij geteeld zijn, niet vervoerd kunnen worden, zonder verlies bij den verkoop op de plants van verscheping. De koffijplanters en suikerfabriekanten zullen dan een bedrijf moeten staken, dat geen redelijke winst meer oplevert, waarbij de bevolking haren arbeid en hare verdiensten verliest en geene Nederlandsche voortbrengselen meer zal kunnen koopen; waaronder onze handel, scheepvaart en fabrieken zullen lijden, daar de aangevoerde goederen meerendeels onverkoopbaar te Samarang zullen blijven liggen; dan zal men inzien dat de welvaart en bloei van Nederland even groote behoefte aan spoorwegen op Java als op eigen grond heeft. De nadeelige gevolgen, uit het gebrek aan voldoende middelen van vervoer voortvloeijende, kunnen niet lang meer uitblijven: Immers nu reeds moet er $f 2 \frac{1}{2}$ besteed worden voor het vervoer van een pikol koffij of suiker uit de binnenlanden naar Samarang; bij lage en zelfs gemiddelde prijzen, kunnen die voortbrengselen zulke hooge transportkosten niet dragen. In de residentiën Sourakarta, Djocdjocarta, Bagelen en Kadoe, die ligt een half millioen pikols suiker zouden kunnen voortbrengen, kunnen die fabrieken niet opgerigt worden noch bloeijen; men kan er de noodige machinerien niet brengen zonder zulke énorme kosten te veroorzaken, dat ieder bedachtzaam ondernemer er door afgeschrikt moet worden. Verlangt men nu uitbreiding van produktie, scheepvaart en handelsvertier van Nederlandsche voortbrengselen, dan moet men de handen in eenslaan en trachten spoorwegen op Java te verkrijgen.

$\mathrm{Nu}$ wij in voordeelige finantiele omstandigheden verkeeren, kan geldgebrek althans geen hinderpaal wezen. De Indische baten hebben reeds vele jaren gestrekt om hoogst aanzienlijke sommen tot delging der nationale schuld ann te wenden, die stellig produktiever tot den aanleg van spoorwegen op Java hadden kunnen besteed worden. Zijn wij roorts wel onderrigt, dan heeft de tegenwoordige minister van kolonien daartoe reeds voor twaalf jaren voorstellen gedaan, die toen op de ongezindheid van het Opperbestuur zouden afgestuit zijn. De toenmalige voorsteller 
is thans minister van kolonien en heeft reeds sedcrt twee jaren de magt en middelen in handen, om gevolg te kunnen geven aan die vroegere voorstellen, van wier noodzakelijkheid hij in $18 \frac{47}{4}$ volkomen overtuigd moet ziju geweest. De wijze evenwel waarop thans dat onderwerp door dien bewindsman ter hand wordt genomen, bevredigt ons geenszins, doch geeft veeleer eenige twijfel omtrent het definitievelijk welgelukken der zaak. Na twee jaren de middelen bezeten en met de vereischte magt bekleed te zijn geweest, is het resultaat ran al die kennis en ondervinding, van dat persoonlijk onderzoek in loco, dat de minister een paar ambtenaren benoemt, die aan Indië vreemd zijn en zich díáll zullen moeten doen voorlichten door manneu van ondervinding en der zake kundig, angezien het in Indië niet aan uitstekend bekwame en met uitgebreide lokale kennis toegeruste ingenieurs ontbreekt. Zal nu niet het gevolg zijn, even als met de suikerkontrakten het geval is geweest, dat zonder te bedenken dat tijd geld is, deze hoogst gewigtige zaak weder eenige jaren verschoven wordt! (*)

Indien het ons is mogen gelukken de gegrondheid en regtmatigheid der klagten van den Samarangschen handelswet door feiten te staven, afgeleid uit den onvoldoenden toewas van den veestapel, vergeleken bij de jaren $1839-1846$ en in verhouding tot de tegenwoordige behocften, dan kan er ook geen twijfel bestaan omtrent de reden van bezorgdheid voor de toekomst, die door de Nederlandsche belanghebbenden gedeeld zal worden. Zullen zij lijdelijk toezien en wachten tot dat, welligt na drie of vier

(*) Wij hebben gaarne een plaats ingeruimd aan het bovenstainde, om de belangstelling in het zoo gewigtig onderwerp van spoorwegen op Java te bevorderen: Deze beschouwingen echter over de thans benoemde commissie, laten wij geheel voor rekening van den schrijver, evenmin als wij ons met het verwijt aan de regering, wegens het dralen bij de invoering van spoorwegen kunnen vereenigen. Althans wie zou kunnen goedkeuren dat men over eene zask als deze ecn bcsluit tot uitvoaring nain, eer roldoende technisch onderzocht is if, en op welke wijze zij best doenlijk is, en welke, nit verschillende oogpunten, de lijnen zullen ziju?Zoo sprak men vroeger b. v. van een spoorweg ovcr geheel Java (in de lengte nl.) terwijl thans door velen wordt angenomen dat afzonderlijke wegen in sommige residentien te verkiezen zijn.

Ja, daar producten- en materialen-vervoer hier wel de hoofdzak is, en de voorwaarde van grooten spoed minder alles beheerscht als in Europa, zoo doet zich, onzes inziens, zclfs de vrang voor, of de eenvoudige, smalle, verlegbarc sporen, dic men meer en meer in landbouw-ondernemingen gebezigd ziet, en warop een anntal wagens door menschenhanden of trekvee worden voortbewogen, - welke sporen dan op één stamlijn konden uitloopen, - niet in cen groot gedeelte der bchoefte zouden kunnen voorzien.

Degelijke overweging behoort dan in elk geval wel vooraf to gatan, hoe men ook van de noodzakelijkheid van uitvoeriuq ; in beginsel moge overtuiged zijn. RE.D. 
jaren, do nu naar Indie vertrekkende ambtenaren, een even volumincus rapport over spoorwegen zullen indienen als over de suikerkwestie is uitgebragt, die, getuige het onlangs verschenen besluit, naar onze meening, er zoo weinig door gebaat, noch bevorderd is! Wij vertrouwen dat de Nederlandsche reeders, handelaren en fabrikanten zullen beseffen, dat, in het algemeen en in hun bijzonder belang, op hen de verpligting rust, om hunnen zedelijken invloed aan te wenden ter verkrijging van hetgeen zoo dringend noodig schijnt. Wij hopen dat zij zich vereenigd bij de planters van Sourakarta en de handelaren van Samarang zullen aansluiten, ten einde de Regering door duidelijke, krachtige vertoogen en petitien, - zoo als vele gemeenten deden de, geen lang uitstel gedoogende, noodzakelijkheid van spoorwegen op Java an te toonen en op meer spoed in de beslissing aan te dringen dan de dezer dagen bekend geworden maatregel verwachten laat. Moge deze regelen tot opwekking daartoe kunnen strekken, dan is er eenige hoop dat de Samarangsche handel, onze scheepvaart en industrie, niet zullen afnemen of verloopen, zoo als men nu vreest en voorziet.

W. BOSCH.

Arnhem, 15 Junij 1860 . 